\title{
ARTICLE
}

Health issues and nutrition in the elderly

\section{Prevalence of malnutrition and analysis of related factors in elderly patients with COVID-19 in Wuhan, China}

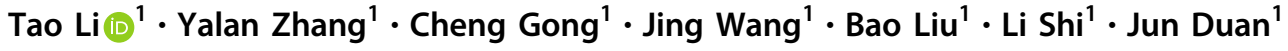

Received: 9 March 2020 / Revised: 1 April 2020 / Accepted: 8 April 2020 / Published online: 22 April 2020

(c) The Author(s), under exclusive licence to Springer Nature Limited 2020

\begin{abstract}
Background/objectives To evaluate the prevalence of malnutrition and its related factors in elderly patients with COVID-19 in Wuhan, China.

Subjects/methods In a cross-sectional study, we evaluated the nutritional status of elderly inpatients with COVID-19 using the Mini Nutritional Assessment (MNA). Based on MNA scores, patients were divided into non-malnutrition group (MNA $\geq$ 24), the group with risk of malnutrition (MNA 17-23.5) and malnutrition group (MNA score < 17). Regression analysis was conducted to screen for risk factors for malnutrition.

Results A total of 182 patients were included in the study, of which $27.5 \%$ were in the group with malnutrition risk and $52.7 \%$ were in the malnutrition group. There were statistical differences in the incidence of comorbid diabetes mellitus, body mass index (BMI), calf circumference,albumin, hemoglobin, and lymphocyte counts among the three groups. Further regression analysis suggested that combined diabetes, low calf circumference, and low albumin were independent risk factors for malnutrition.

Conclusions The prevalence of malnutrition in elderly patients with COVID-19 was high, and nutritional support should be strengthened during treatment, especially for those with diabetes mellitus, low calf circumference, or low albumin.
\end{abstract}

\section{Introduction}

A novel coronavirus (SARS-CoV-2) has been identified as originating in Wuhan, Hubei province, China [1]. It has widely and rapidly spread in China and several other countries, causing an outbreak of COVID-19 [2]. Although the population is generally susceptible to SARS-CoV-2, most of the patients who need to be admitted to hospital are elderly or with chronic underlying diseases [3]. Clinical observations have found that many elderly patients with COVID-19 are at risk of malnutrition or co-malnutrition. Moreover, SARS-CoV-2 can attack the mucosal epithelium and cause gastrointestinal symptoms, which further damage the nutritional status of elderly patients [4]. In order to scientifically evaluate the nutritional status of elderly patients with COVID-19, we

Jun Duan

junjununun@163.com

1 China-Japan Friendship Hospital, Beijing, China conducted the cross-sectional study. To our knowledge, this is the first study to evaluate the state of nutrition in elderly patients with COVID-19.

\section{Subjects and methods}

\section{Subjects}

This cross-sectional study was performed in COVID-19 patients admitted to sino-french new city branch of Wuhan Tongji Hospital from January to February 2020. All patients were confirmed with 2019-nCov infection by real-time PCR and next-generation sequencing. Ineligibility criteria were as follows: (1) Age $<65$ years; (2) Incomplete questionnaire; (3) Incompatible with anthropometry; (4) Severe hepatic dysfunction; (5) Severe renal dysfunction. Overall, 182 patients were included in the analysis (Fig. 1). This study was conducted according to the World Medical Association Declaration of Helsinki and was approved by Ethics Committee of China-Japan Friendship Hospital. Written informed consent was obtained from all subjects. 


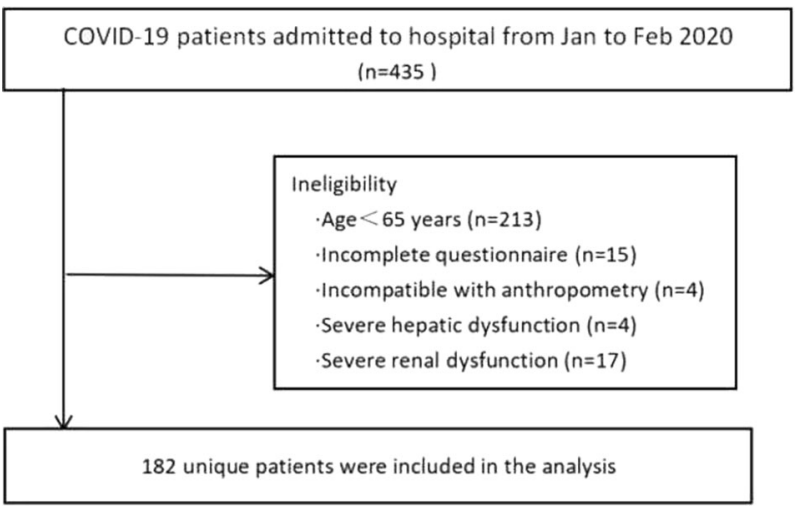

Fig. 1 Flow of patients in the study.

\section{Demographics, comorbidities, and laboratory values}

Demographic characteristics, such as patient age and sex, were extracted from the electronic medical record. The comorbidities were determined by patients' reports of past medical history diagnosed hypertension, diabetes mellitus, cerebrovascular disease, cardiovascular disease, chronic lung disease. Blood tests drawn on admission were extracted from the electronic medical record including albumin and blood count (hemoglobin and lymphocyte count).

\section{Anthropometric measures}

Anthropometric measures were taken by a trained medical graduate and measured as per the standard measurement guidelines [5]. Body height (to the nearest $0.1 \mathrm{~cm}$ ) and weight (to the nearest $0.1 \mathrm{~kg}$ ) in light indoor clothing were measured. Body mass index $\left(\mathrm{kg} / \mathrm{m}^{2}\right)$ was calculated. Skinfold thickness, which was measured using Harpenden caliper, was calibrated to the accuracy of $\pm 1 \mathrm{~mm}$. For midarm circumference, triceps skin-fold thickness, and calf circumference, average of left and right side measurements was considered for analysis.

\section{Nutritional assessment}

MNA was developed for the elderly specifically and consisted of 18 questions [6]. In the dietary questionnaire section of the MNA, the cheese item, due to extremely infrequent consumption among Chinese, was replaced by soymilk and peanut milk while other items remained the unchanged. Questionnaire assessments were completed through face-to-face interviews and were performed by the staff trained well in formal nutrition surveys. Nutritional status was assessed considering the following cutoff points: $<17$ points (malnutrition); 17-23.5 points (risk of malnutrition) and 24-30 points (non-malnutrition) [7, 8].

\section{Statistical analysis}

Continuous variables were expressed as mean \pm SD. Categorical variables were expressed as absolute values and percentages. Paired student's $t$-test, chi-square, ANOVA and Fisher's exact tests were used to compare values of variables between groups. Bonferroni test was used for correction of multiple testing errors of results from ANOVA. Pearson's chi-square $\left(\chi^{2}\right)$ test or Fisher's exact test were used to assess the association between each of the discrete variables and patients' malnutrition status. Factors associated with malnutrition in the univariate analysis $(p<$ 0.10 ) were then included in multivariable regression model. Stepwise selection method for logistic regression model was used to identify the independent risk factors. Statistical tests were considered significant if $P<0.05$. All statistical analyses were performed in SPSS (V.22.0, IBM, Chicago, USA).

\section{Results}

Among 182 patients, 65 were male and 117 were female, with mean age $68.5 \pm 8.8$ years old. Average MNA score was $22.9 \pm 2.8$. Across all patients, $52.7 \%(n=96)$ were malnourished, $27.5 \%(n=50)$ were at risk of malnutrition. There was no difference in age, gender composition, and comorbidities among the three groups. In terms of anthropometry, there were also no differences in triceps skin-fold thickness and mid-arm circumference. There were statistical differences in the incidence of comorbid diabetes mellitus, body mass index (BMI), calf circumference, albumin, hemoglobin, and lymphocyte counts among the three groups. The basic demographic, comorbidities, anthropometry, and laboratory values of all enrolled patients showed in Table 1.

Further regression analysis suggested that combined diabetes (OR 2.12; 95\% CI 1.92-3.21), low calf circumference (OR 2.42; 95\% CI 2.29-3.53), and low albumin (OR 2.98; 95\% CI 2.43-5.19) were independent risk factors for malnutrition (Table 2).

\section{Discussion}

SARS-CoV-2 was a commonly susceptible RNA virus that had spread to 25 countries or regions [9], and the number of confirmed infections named COVID-19 had exceeded 70,000 in China $[1,5]$. Pulmonary infection was the main disease induced by the virus and was called neo-coronavirus pneumonia [10]. Currently, there was still lack of effective specific drug treatment in clinical practice, and supportive treatment was still the main treatment $[11,12]$. The overall 
Table 1 Clinical features of the three groups.

\begin{tabular}{|c|c|c|c|c|c|c|}
\hline Features & $\begin{array}{l}\text { All included } \\
\text { patients }(n=182)\end{array}$ & $\begin{array}{l}\text { Non-malnutrition } \\
(n=36)\end{array}$ & $\begin{array}{l}\text { Risk of malnutrition } \\
(n=50)\end{array}$ & $\begin{array}{l}\text { Malnutrition } \\
(n=96)\end{array}$ & $\begin{array}{l}\mathrm{F} \text { 或 } \\
\chi^{2} \text { value }\end{array}$ & $P$ value \\
\hline MNA score & $22.9 \pm 2.8$ & $26.4 \pm 1.4$ & $21.5 \pm 1.3$ & $15.1 \pm 2.5$ & 6.135 & 0.018 \\
\hline Age(years) & $68.5 \pm 8.8$ & $68.1 \pm 8.1$ & $69.5 \pm 7.3$ & $69.8 \pm 8.2$ & 1.368 & 0.137 \\
\hline $\operatorname{Sex}(M / F)$ & $65 / 117$ & $14 / 22$ & $17 / 33$ & $34 / 62$ & 1.182 & 0.638 \\
\hline Hypertension (\%) & $29(15.9)$ & $5(13.9)$ & $8(16.0)$ & $16(16.7)$ & 1.036 & 0.725 \\
\hline Diabetes mellitus (\%) & $51(28.0)$ & $6(16.7)$ & $11(22.0)$ & $34(35.4)$ & 6.527 & 0.015 \\
\hline Cerebrovascular disease $(\%)$ & $17(9.34)$ & $3(8.33)$ & $5(10.0)$ & $9(9.38)$ & 2.337 & 0.532 \\
\hline Cardiovascular disease $(\%)$ & $19(10.4)$ & $4(11.1)$ & $5(10.0)$ & $10(10.4)$ & 1.028 & 0.768 \\
\hline Chronic lung disease (\%) & $15(8.24)$ & $3(8.33)$ & $4(8.00)$ & $8(8.33)$ & 0.683 & 0.825 \\
\hline BMI $\left(\mathrm{kg} / \mathrm{m}^{2}\right)$ & $24.8 \pm 4.1$ & $25.6 \pm 3.0$ & $23.3 \pm 3.4$ & $21.1 \pm 3.6$ & 4.106 & 0.035 \\
\hline $\begin{array}{l}\text { Triceps skin-fold } \\
\text { thickness }(\mathrm{mm})\end{array}$ & $15.6 \pm 8.1$ & $16.8 \pm 7.2$ & $15.7 \pm 6.9$ & $14.9 \pm 7.3$ & 1.632 & 0.126 \\
\hline Mid-arm circumference $(\mathrm{cm})$ & $28.2 \pm 3.7$ & $28.7 \pm 2.8$ & $27.6 \pm 3.3$ & $26.5 \pm 3.2$ & 2.679 & 0.379 \\
\hline Calf circumference $(\mathrm{cm})$ & $31.8 \pm 6.1$ & $33.4 \pm 5.6$ & $31.2 \pm 4.8$ & $28.7 \pm 5.7$ & 2.518 & 0.047 \\
\hline Albumin $(\mathrm{g} / \mathrm{L})$ & $34.1 \pm 6.8$ & $38.5 \pm 4.2$ & $30.1 \pm 6.4$ & $25.7 \pm 5.3$ & 10.217 & $<0.001$ \\
\hline Hemoglobin $(\mathrm{g} / \mathrm{L})$ & $113.2 \pm 18.7$ & $126.4 \pm 12.3$ & $111.5 \pm 15.2$ & $98.4 \pm 13.4$ & 9.754 & $<0.001$ \\
\hline Lymphocyte count $\left(\times 10^{9} / \mathrm{L}\right)$ & $1.4 \pm 0.57$ & $1.7 \pm 0.52$ & $1.2 \pm 0.43$ & $0.9 \pm 0.38$ & 11.237 & $<0.001$ \\
\hline
\end{tabular}

Table 2 Multiple logistic regression models for the variables associated with malnutrition.

\begin{tabular}{llllllll}
\hline Variables & B & SE & Wald & df & OR & $P$ value & $95 \%$ CI \\
\hline $\begin{array}{l}\text { Diabetes } \\
\text { mellitus }\end{array}$ & 0.076 & 0.036 & 8.322 & 1 & 2.12 & 0.006 & $1.92-3.21$ \\
$\begin{array}{l}\text { Calf } \\
\text { circumference }\end{array}$ & 0.682 & 0.419 & 6.352 & 1 & 2.42 & 0.027 & $2.29-3.53$ \\
\begin{tabular}{l} 
Albumin \\
\hline
\end{tabular} & 0.618 & 0.526 & 7.367 & 1 & 2.98 & 0.005 & $2.43-5.19$ \\
\hline
\end{tabular}

prognosis of elderly patients was worse than that of young and middle-aged patients. One reason may be the poor nutritional status of elderly patients. Our cross-sectional study found that $27.5 \%$ of patients over 65 years old were at risk of malnutrition and $52.7 \%$ were malnourished, which was generally higher than that of elderly patients with other disease spectrums [13].

Malnutrition was a nutritional disorder that caused adverse reactions to normal human functioning and was more common in elderly patient groups [14]. A study that summarized 12 countries or regions found that the overall incidence of malnutrition in the elderly was about $23 \%$, with a $50.5 \%$ higher incidence in rehabilitation institutions and a $38.7 \%$ incidence in hospitalized patients [15]. The incidence of malnutrition in elderly patients with COVID19 was higher. The main reasons may be as follows. First, the protein that made up muscles was consumed by the acute inflammatory response of neo-coronavirus infection. Patients' inflammation indicators increased generally, such as C-reactive protein, ferritin, tumor necrosis factor alpha, interleukin family factors, etc [16]. The synthesis of these acute-phase proteins required the consumption of albumin and even muscle protein [16]. This was consistent with the results of the regression analysis of the study. The patient's albumin level and calf circumference were significantly lower. Similarly, hypoalbuminemia and low calf circumference were commonly used as important indicators for evaluating malnutrition [17, 18]. Second, among elderly patients with COVID-19, comorbidity in diabetes mellitus was much more than general population. In other words, high rates of comorbid diabetes mellitus led to higher rates of malnutrition in elderly patients with COVID-19. Diabetes patients due to their own internal glandular dysfunction, had disorders in metabolism of the three major nutrients, which was the internal cause of malnutrition $[19,20]$. At the same time, diabetic patients' diet control, improper nutrient ratio and other factors were external causes of malnutrition [21]. Moreover, the inflammatory response caused by SARS-CoV-2 and the application of glucocorticoids resulted in fluctuations in blood glucose, which was related to pathogenesis [22]. Third, gastrointestinal symptoms caused by SARS-CoV-2 exacerbated malnutrition in elderly patients. Angiotensin-converting enzyme 2 was also highly expressed in the gastrointestinal track [23]. So the gastrointestinal tract was also the main target of SARS-CoV-2 attack [24, 25]. Clinically, in addition to respiratory symptoms, gastrointestinal symptoms were the most in elderly patients with COVID-19. Diarrhea, mild abdominal pain, nausea, vomiting, poor appetite, and other symptoms were very common [26]. The involvement of the digestive tract had accelerated the occurrence of malnutrition in elderly patients with COVID-19. Fourth, the 
poor appetite of the patients was also related to the patient's anxiety [27]. The Chinese experienced the epidemic of SARS induced by coronavirus in 2003, just like COVID-19. People were so impressed with the SARS epidemic that many patients still had psychological problems after 6 years [28]. Therefore, Chinese were very sensitive to COVID-19, and its epidemic could easily cause anxiety among patients. Patients' fear of their own illness, worrying about long-term isolation, and desire for normal social communication, led to anxiety, which further reduced the appetite of the patient and further aggravated malnutrition. At the same time, anxiety disrupted homeostasis [29], which was also a contributing factor to malnutrition.

There are some limitations in the present study. First, it was a single-center study. The hospital for treating patients with COVID-19 was designated by government. And admitted patients were also designated by the government. So there must be some selective bias. Second, there must be some other risk factors, such as lifestyle habits, physical activity and social support, may also significantly affect the nutritional conditions of patients, but these factors were not analyzed in the current study. Hence, more future studies need to be carried out to further clarify these issues.

In conclusion, there was a high prevalence of malnutrition in elderly patients with COVID-19 in Wuhan, China. For clinical practice, nutritional support should be strengthened, especially for elderly patients with diabetes mellitus, low calf circumference, or low albumin.

Acknowledgements We would like to express our thanks to all patients with COVID-19.

Author contributions Conceived and designed the study: TL, LS, and JD. Performed the study: TL, BL, YZ, JW, and CG. Analyzed the date: TL. Wrote the manuscript: TL. Reviewed the manuscript: LS and JD. All author approved the final version of the manuscript.

\section{Compliance with ethical standards}

Conflict of interest The authors declare that they have no conflict of interest.

Publisher's note Springer Nature remains neutral with regard to jurisdictional claims in published maps and institutional affiliations.

\section{References}

1. Ralph R, Lew J, Zeng T, Francis M, Xue B, Roux M, et al. 2019nCoV (Wuhan virus), a novel coronavirus: human-to-human transmission, travel-related cases, and vaccine readiness. J Infect Dev Ctries. 2020;14:3-17.

2. Rubin EJ, Baden LR, Morrissey S. Audio interview: preparing for the spread of Covid-19. N Engl J Med. 2020;382:e18.

3. $\mathrm{Xu} \mathrm{XW,} \mathrm{Wu} \mathrm{XX,} \mathrm{Jiang} \mathrm{XG,} \mathrm{Xu} \mathrm{KJ,} \mathrm{Ying} \mathrm{LJ,} \mathrm{Ma} \mathrm{CL,} \mathrm{et} \mathrm{al.}$ Clinical findings in a group of patients infected with the 2019 novel coronavirus (SARS-Cov-2) outside of Wuhan, China: retrospective case series. BMJ. 2020;368:m606.

4. Huang C, Wang Y, Li X, Ren L, Zhao J, Hu Y, et al. Clinical features of patients infected with 2019 novel coronavirus in Wuhan, China. Lancet. 2020;395:497-506.

5. World Health Organization. Physical Status: The Use and Interpretation of Anthropometry. Report of a WHO Expert Committee. Geneva: WHO; 1995. http://www.apps.who.int/iris/bitstream/10665/ 37003/1/WHO_TRS_854.pdf?ua=1. Accessed 7 July 2015.

6. Vellas B, Guigoz Y, Garry PJ, Nourhashemi F, Bennahum D, Lauque S, et al. The Mini Nutritional Assessment (MNA) and its use in grading the nutritional state of elderly patients. Nutrition. 1999;15:116-22.

7. Guigoz Y, Lauque S, Vellas BJ. Identifying the elderly at risk for malnutrition. Mini Nutritional Assess Clin Geriatr Med. 2002;18:737-57.

8. Agarwal E, Miller M, Yaxley A, Isenring E. Malnutrition in the elderly: a narrative review[J]. Maturitas. 2013;76:296-302.

9. Dilcher M, Werno A, Jennings LC. SARS-CoV-2: a novel deadly virus in a globalised world. N Z Med J. 2020;133:6-11.

10. Song F, Shi N, Shan F, Zhang Z, Shen J, Lu H. et al. Emerging coronavirus 2019-nCoV pneumonia. Radiology. 2020;295:210-7.

11. Zhang J, Zhou L, Yang Y, Peng W, Wang W, Chen X. Therapeutic and triage strategies for 2019 novel coronavirus disease in fever clinics. Lancet Respir Med. 2020;8:e11-e12.

12. Pang J, Wang MX, Ang IYH, Tan SHX, Lewis RF, Chen JI, et al. Potential rapid diagnostics, vaccine and therapeutics for 2019 novel coronavirus (2019-nCoV): a systematic review. J Clin Med. 2020;9:E623.

13. Corcoran C, Murphy C, Culligan EP, Walton J, Sleator RD. Malnutrition in the elderly. Sci Prog. 2019;102:171-80.

14. Holder H. Malnutrition in the elderly: a public health concern. $\mathrm{Br}$ J Nurs. 2020;29:118-9.

15. Kaiser MJ, Bauer JM, Rämsch C, Uter W, Guigoz Y, Cederholm $\mathrm{T}$, et al. Frequency of malnutrition in older adults: a multinational perspective using the mini nutritional assessment. J Am Geriatr Soc. 2010;58:1734-8.

16. Jia H. Pulmonary angiotensin-converting enzyme 2 (ACE2) and inflammatory lung disease. Shock. 2016;46:239-48.

17. Ohwada H, Nakayama T, Kanaya Y, Tanaka Y. Serum albumin levels and their correlates among individuals with motor disorders at five institutions in Japan. Nutr Res Pr. 2017;11:57-63.

18. Maeda K, Koga T, Nasu T, Takaki M, Akagi J. Predictive accuracy of calf circumference measurements to detect decreased skeletal muscle mass and European Society for Clinical Nutrition and Metabolism-Defined Malnutrition in Hospitalized Older Patients. Ann Nutr Metab. 2017;71:10-15.

19. Phielix E, Mensink M. Type 2 diabetes mellitus and skeletal muscle metabolic function. Physiol Behav. 2008;94:252-8.

20. Hughes S. Diabetes: support for those at risk of malnutrition in the community[J]. Br J Community Nurs. 2012;17:529-30.

21. Donnelly A. Nutritional requirements in malnutrition and diabetes mellitus. Nurs Stand. 2018;33:69-76.

22. Johnson AO, Agbedana EO, Adeyemo RO. Interrelationships of blood glucose, cortisol, insulin and albumin in protein-energy malnutrition. East Afr Med J. 1980;57:745-50.

23. Hamming I, Timens W, Bulthuis ML, Lely AT, Navis G, van Goor $\mathrm{H}$. Tissue distribution of ACE2 protein, the functional receptor for SARS coronavirus. A first step in understanding SARS pathogenesis. J Pathol. 2004;203:631-7.

24. Duarte R, Furtado I, Sousa L, Carvalho CFA. The 2019 novel coronavirus (2019-nCoV): novel virus, old challenges. Acta Med Port. 2020;33:1-3.

25. Kuhn JH, Li W, Choe H, Farzan M. Angiotensin-converting enzyme 2: a functional receptor for SARS coronavirus. Cell Mol Life Sci. 2004;61:2738-43. 
26. Guan WJ, Ni ZY, Hu Y, Liang WH, Ou CQ, He JX, et al. Clinical characteristics of Coronavirus disease 2019 in China. N Engl J Med. 2020. https://www.nejm.org/doi/full/10.1056/NEJMoa2002032.

27. Mattar L, Huas C, Duclos J, Apfel A, Godart N. Relationship between malnutrition and depression or anxiety in Anorexia Nervosa: a critical review of the literature. J Affect Disord. 2011;132:311-8.
28. Mak IW, Chu CM, Pan PC, Yiu MG, Chan VL. Long-term psychiatric morbidities among SARS survivors. Gen Hosp Psychiatry. 2009;31:318-26.

29. Lambrinakou S, Katsa ME, Zyga S, et al. Correlations between nutrition habits, anxiety and metabolic parameters in Greek Healthy Adults. Adv Exp Med Biol. 2017;987:23-34. 